\title{
LIBERALISMO VERSUS ANARCOCAPITALISMO
}

\author{
JESÚS HUERTA DE SOTO*
}

Resumen: En el presente trabajo se explica por qué el programa del liberalismo clásico es teórica y prácticamente imposible, y por qué el único sistema de cooperación social plenamente compatible con la naturaleza del ser humano es el anarcocapitalismo.

Palabras clave: Liberalismo, anarcocapitalismo, socialismo, estatismo, empresarialidad.

Abstract: This article explains why the ideal of classical liberalism is theoretically and practically impossible, as well as that the only system of social cooperation theoretically possible and wholly compatible with human nature is anarcocapitalism.

Key words: Classical liberalism, anarcocapitalism, socialism, statism, entrepreneurship.

Códigos JEL: B53, D83, H11, H77, P17.

* Catedrático de Economía Política, Universidad Rey Juan Carlos, Madrid. Web: www.jesushuertadesoto.com, correo: huertadesoto@dimasoft.es

El presente artículo es la versión escrita de sendas conferencias del mismo título pronunciadas respectivamente en la Universidad de Verano de la Universidad Rey Juan Carlos (Aranjuez, viernes 6 de julio de 2007) y en la Universidad de Verano de la Universidad Complutense (San Lorenzo de El Escorial, lunes 16 de julio de 2007). En ellas se oficializa mi «ruptura» teórica y política con el liberalismo clásico, que queda superado en la natural evolución hacia el anarcocapitalismo que ya insinuaba claramente en mi intervención de Septiembre de 2000 en Santiago de Chile ante la Asamblea General de la Mont Pèlerin Society, en una ponencia compartida con James Buchanan y Bruno Frei (Huerta de Soto 2002, 239-245). 


\section{I \\ INTRODUCCIÓN}

El pensamiento liberal teórico y político se encuentra en esta primera década del siglo XXI en una encrucijada de trascendental importancia. Aunque la caída del Muro de Berlín y del socialismo real a partir de 1989 parecieron anunciar «el fin de la historia» (en la tan infeliz como rimbombante expresión de Francis Fukuyama), lo cierto es que hoy, y en muchos aspectos más que nunca, impera por doquier el estatismo y la desmoralización de los amantes de la libertad. Es urgente y se hace preciso, por tanto, un «aggiornamento» del liberalismo, es decir, una profunda revisión y puesta al día del ideario liberal a la luz de los últimos avances de la Ciencia Económica y de la experiencia acumulada en los últimos acontecimientos históricos. El punto de partida fundamental de esta revisión consiste en reconocer que el liberalismo clásico ha fracasado en su intento de limitar el poder del estado y que hoy la ciencia económica está en disposición de explicar el por qué este fracaso era inevitable. A su vez, la teoría dinámica de los procesos de cooperación social impulsados por la empresarialidad que da lugar al orden espontáneo del mercado se generaliza y convierte en todo un análisis del sistema anarcocapitalista de cooperación social que surge como el único sistema verdaderamente viable y compatible con la naturaleza del ser humano.

En el presente artículo se analizan con detalle estas cuestiones junto con una serie de consideraciones complementarias de tipo práctico y de estrategia científica y política. Además, se aprovecha el análisis contenido en el mismo para aclarar determinados malentendidos y errores de interpretación que a menudo suelen plantearse.

II

\section{EL ERROR FATAL DEL LIBERALISMO CLÁSICO}

El error fatal de los liberales clásicos radica en no haberse dado cuenta de que el programa del ideario liberal es teóricamente imposible pues incorpora dentro de sí mismo la semilla de su 
propia destrucción, precisamente en la medida en que considera necesaria y acepta la existencia de un estado (aunque sea mínimo) entendido como la agencia monopolista de la coacción institucional.

Por tanto, el gran error de los liberales es de planteamiento: piensan que el liberalismo es un programa de acción política y doctrina económica que tiene por objetivo limitar el poder del estado, pero aceptándolo e incluso considerando necesaria su existencia. Sin embargo, hoy (en la primera década del siglo XXI), la Ciencia Económica ya ha puesto de manifiesto: (a) que el estado no es necesario; (b) que el estatismo (aunque sea mínimo) es teóricamente imposible; y (c) que, dada la naturaleza del ser humano, una vez que existe el estado es imposible limitar su poder. Comentaremos por separado cada uno de estos aspectos.

III

\section{EL ESTADO COMO ENTE INNECESARIO}

Desde el punto de vista científico, solo desde el equivocado paradigma del equilibrio puede llegar a pensarse que exista una categoría de «bienes públicos» en los que, por darse los requisitos de oferta conjunta y no rivalidad en el consumo, se justificaría prima facie la existencia de una agencia monopolista de la coacción institucional (estado) que obligara a todos a financiarlos.

Sin embargo, la concepción dinámica del orden espontáneo impulsado por la función empresarial que ha desarrollado la Escuela Austriaca de Economía ha echado por tierra toda esta teoría justificativa del estado: siempre que surge una situación (aparente o real) de «bien público», i.e. de oferta conjunta y no rivalidad en el consumo, surgen los incentivos necesarios para que el ímpetu de la creatividad empresarial la supere mediante las innovaciones tecnológicas, jurídicas y los descubrimientos empresariales que hacen posible la solución de cualesquiera problemas que pudieran plantearse (siempre y cuando el recurso no sea declarado "público» y se permita el libre ejercicio de la función empresarial y la concomitante apropiación privada de los resultados de cada acto de creatividad empresarial). Así, por 
ejemplo, el sistema de faros marítimos fue durante mucho tiempo de titularidad y financiación privada en el Reino Unido, lográndose por procedimientos privados (asociaciones de navegantes, precios portuarios, control social espontáneo, etc.) solventar el «problema» de lo que se considera en los libros de texto de economía «estatistas» el caso más típico de «bien público». Igualmente, en el lejano oeste norteamericano se planteó el problema de la definición y defensa del derecho de propiedad de, por ejemplo, las reses de ganado en amplísimas extensiones de tierra, introduciéndose paulatinamente diversas innovaciones empresariales («marcaje» de las reses, vigilancia continua por «cow-boys» a caballo armados y, finalmente, el descubrimiento e introducción del alambre de espino que, por primera vez, permitió la separación efectiva de grandes extensiones de tierra a un precio muy asequible) que solucionaron los problemas conforme se iban planteando. Todo este flujo creativo de innovaciones empresariales se habría bloqueado por completo si los recursos hubieran sido declarados "públicos», excluidos de la propiedad privada y gestionados burocráticamente por una agencia estatal. ( $Y$ así, hoy en día, por ejemplo, la mayoría de calles y carreteras están cerradas a la introducción de innumerables innovaciones empresariales - como el cobro de precio por vehículo y hora, la gestión privada de la seguridad, de la polución acústica, etc.- y ello a pesar de que la mayoría ya no plantean problema tecnológico alguno, pues dichos bienes han sido declarados «públicos» imposibilitándose así su privatización y gestión creativa empresarial).

Además, a nivel popular se piensa que el estado es necesario porque se confunde la existencia del mismo (innecesaria) con el carácter imprescindible de muchos de los servicios y recursos que hoy (malamente) oferta (casi siempre so pretexto de su carácter público) con carácter exclusivo. Los seres humanos observan que hoy en día las carreteras, los hospitales, las escuelas, el orden público, etc. etc., son proporcionados en gran (sino en exclusiva) medida por el estado, y como son muy necesarios, concluyen sin más análisis que el estado es también imprescindible. No se dan cuenta de que los recursos citados pueden producirse con mucha más calidad y de forma más eficiente, barata, y conforme con las cambiantes y variadas necesidades de cada persona, a través del 
orden espontáneo del mercado, la creatividad empresarial y la propiedad privada. Además, caen en la trampa de creer que el estado es también necesario para proteger a los indefensos, pobres y desvalidos (sean «pequeños» accionistas, consumidores de a pie, trabajadores, etc.) sin entender que las supuestas medidas de protección sistemáticamente tienen el efecto, como demuestra la teoría económica, de perjudicar en cada caso precisamente a aquellos a los que se dice proteger, por lo que desaparece también una de las más burdas y manidas justificaciones de la existencia del estado.

Decía Rothbard que el conjunto de los bienes y servicios que actualmente proporciona el estado se dividen, a su vez, en dos subconjuntos: el de aquellos que hay que eliminar y el de aquellos que es preciso privatizar. Es claro que los bienes citados en el párrafo anterior pertenecen al segundo grupo y que la desaparición del estado, lejos de significar la desaparición de carreteras, hospitales, escuelas, orden público, etc., implicaría su provisión con más abundancia, calidad y a un precio más asequible (siempre en comparación con el coste real que vía impuestos actualmente pagan los ciudadanos). Además, hay que señalar que los casos históricos de caos institucional y desorden público que puedan señalarse (por ejemplo, en muchas ocasiones durante los años previos y durante la Guerra Civil en la Segunda República española, u hoy en día en amplias zonas de Colombia o en Irak) se deben al vacío de provisión de estos bienes creado por los propios estados que ni hacen con un mínimo de eficiencia lo que en teoría deberían hacer según sus propios seguidores, ni dejan hacer al sector privado y empresarial, pues el estado prefiere el desorden (que, además, parece legitimar su presencia coactiva con más intensidad) a su desmantelamiento y privatización a todos los niveles.

Es especialmente importante entender que la definición, adquisición, transmisión, intercambio y defensa de los derechos de propiedad que articulan e impulsan el proceso social, no requieren de una agencia monopolista de la violencia (estado). Y no sólo no la requieren sino que, por el contrario, el estado siempre actúa pisoteando múltiples títulos legítimos de propiedad, defendiéndolos de forma muy deficiente y corrompiendo el comportamiento individual (moral y jurídico) de respeto a los derechos de propiedad privada ajena. 
El sistema jurídico es la plasmación evolutiva que integra los principios generales del derecho (especialmente de propiedad) compatibles con la naturaleza del ser humano. El derecho, por tanto, no es lo que el estado decide (democráticamente o no), sino que está ahí, inserto en la naturaleza del ser humano, aunque se descubra y consolide jurisprudencial y, sobre todo, doctrinalmente de forma evolutiva (en este sentido consideramos que el sistema jurídico de tradición romana y continental, por su carácter más abstracto y doctrinal, es muy superior al sistema anglosajón del common law, que surge de un desproporcionado respaldo del estado a las decisiones o fallos judiciales que, a través del «binding case», introducen en el sistema legal todo tipo de disfunciones provenientes de las circunstancias e intereses particulares que preponderan en cada proceso). El derecho es evolutivo y consuetudinario $y$, por tanto, es previo e independiente del estado y no requiere para su definición y descubrimiento de ninguna agencia monopolista de la coacción.

Y el estado no sólo no es preciso para definir el derecho. Tampoco lo es para hacerlo valer y defenderlo, y esto debe resultar especialmente obvio en los tiempos actuales, en los que el uso -incluso, paradójicamente, por muchos organismos gubernamentalesde empresas privadas de seguridad, está a la orden del día.

No puede pretenderse que expongamos aquí con detalle cómo funcionaría la provisión privada de los que hoy se consideran como «bienes públicos» (aunque el no saber a priori cómo solucionaría el mercado infinidad de problemas concretos es la objeción ingenua y fácil de aquellos que prefieren el statu quo actual so pretexto de que «más vale lo malo conocido que lo bueno por conocer»). ${ }^{1}$ De hecho, no pueden conocerse hoy las soluciones empresariales que un ejército de emprendedores daría a los problemas planteados — si se les dejase hacerlo-. Pero lo que hasta los más escépticos han de reconocer es que «lo que hoy ya se sabe» es que el mercado, impulsado por la empresarialidad creativa, funciona y precisamente lo hace en la medida en que el estado no interviene coactivamente en su proceso social. Y que las

1 Véase, entre otros, el artículo de Albert Esplugas incluido en este número de Procesos de Mercado, pp. 205-253 y la bibliografía allí citada (Esplugas, 2007). 
dificultades y conflictos siempre surgen precisamente allí donde no se deja que se desarrolle libremente el orden espontáneo del mercado. Por eso, los teóricos de la libertad (y con independencia del esfuerzo realizado desde Gustav de Molinari hasta hoy imaginando cómo funcionaría la red anarcocapitalista de agencias privadas de seguridad y defensa patrocinadoras cada una de ellas de sistemas jurídicos más o menos marginalmente alternativos) nunca deben de olvidar que precisamente lo que nos impide conocer con exactitud cómo sería un futuro sin estado (el carácter creativo de la función empresarial), es lo que nos da la tranquilidad de saber que cualquier problema tenderá a ser superado al dedicarse a su solución todo el esfuerzo y la creatividad de los seres humanos implicados (Kirzner 1985, 168). Ahora bien, gracias a la Ciencia Económica no sólo sabemos que el mercado funciona, también sabemos que el estatismo es teóricamente imposible.

\section{IV \\ POR QUÉ EL ESTATISMO ES TEÓRICAMENTE IMPOSIBLE}

La teoría económica de la Escuela Austriaca sobre la imposibilidad del socialismo se generaliza (Huerta de Soto 1992, 151153) y convierte en toda una teoría sobre la imposibilidad del estatismo, entendido como el intento de organizar cualquier parcela de la vida en sociedad mediante los mandatos coactivos de intervención, regulación y control procedentes del órgano monopolista de la agresión institucional (estado). Y es imposible que el estado cumpla sus objetivos coordinadores en cualquier parcela del proceso de cooperación social en que pretenda intervenir, incluyendo especialmente los ámbitos del dinero y la banca (Huerta de Soto, 1998), del descubrimiento del derecho, de la impartición de Justicia y del orden público (entendido como la prevención, represión y sanción de los actos criminales), por los siguientes cuatro motivos:

a) Por el enorme volumen de información que necesitaría para ello y que sólo se encuentra de forma dispersa o diseminada 
en los millones de personas que cada día participan en el proceso social.

b) Dado el carácter predominantemente tácito y no articulable (y, por tanto, no transmisible de forma inequívoca) de la información que necesitaría el órgano de intervención para dar un contenido coordinador a sus mandatos.

c) Porque la información que se utiliza a nivel social no está «dada» sino que cambia continuamente como consecuencia de la creatividad humana, siendo obviamente imposible transmitir hoy una información que sólo será creada mañana y que es la que necesita el órgano de intervención estatal para que mañana pueda lograr sus objetivos; y

d) Sobre todo porque el carácter coactivo de los mandatos del estado, y en la medida en que sean cumplidos e incidan con éxito en el cuerpo social, bloquea la actividad empresarial de creación de esa información que es precisamente la que necesita como «agua de mayo» la organización estatal de intervención para dar un contenido coordinador (y no desajustador) a sus propios mandatos.

Además de ser teóricamente imposible, el estatismo genera toda una serie de efectos distorsionadores periféricos muy dañinos: fomento de la irresponsabilidad (al no conocer el estado el coste real de su intervención actúa de forma irresponsable); destrucción del medio ambiente cuando éste es declarado bien público y se impide su privatización; corrupción de los conceptos tradicionales de Ley y Justicia que pasan a ser sustituidos por los de mandato y justicia «social» (Hayek 2006, 25357); corrupción mimética del comportamiento individual que cada vez se hace más agresivo y respeta menos la moral y el derecho.

Este análisis nos permite concluir también que si en la actualidad determinadas sociedades prosperan ello no es por el estado sino, precisamente, a pesar de él (Rodríguez Braun, 1999), pues todavía muchos seres humanos conservan la inercia del comportamiento pautado sometido a leyes en sentido material, siguen existiendo parcelas de mayor libertad relativa y el estado suele ser muy ineficiente a la hora de imponer sus forzosamente 
torpes y ciegos mandatos. Además, incluso hasta los incrementos más marginales de libertad generan notables impulsos de prosperidad, lo que ilustra hasta qué punto podría avanzar la civilización si pudiera desembarazarse de la rémora del estatismo.

Finalmente, ya hemos comentado el espejismo que afecta a todos aquellos que identifican al estado con la provisión de los bienes («públicos») que hoy (costosa y malamente) proporciona, concluyendo erróneamente que la desaparición del estado implicaría necesariamente la desaparición de sus preciados servicios, y ello en un entorno de continuo adoctrinamiento político a todos los niveles (y, especialmente, a través del sistema educativo que ningún estado, por razones obvias, quiere dejar de controlar), de imposición totalitaria de los criterios "políticamente correctos», y de racionalización autocomplaciente del statu quo por parte de una mayoría que se niega a ver lo obvio: que el estado no es sino una entelequia constituida por una minoría para vivir a costa de los demás, a los que primero explota, luego corrompe y después compra con recursos ajenos (impuestos) «favores» políticos de todo tipo.

\section{$\mathrm{V}$ \\ LA IMPOSIBILIDAD DE LIMITAR EL PODER DEL ESTADO: SU CARÁCTER «LETAL» EN COMBINACIÓN CON LA NATURALEZA DEL SER HUMANO}

Una vez que existe el estado es imposible limitar la expansión de su poder. Es cierto que, como indica Hoppe, determinadas formas políticas (como la monarquía absoluta, en la que el Rey-propietario será ceteris paribus más cuidadoso a largo plazo para «no matar a la gallina de los huevos de oro») tenderán a expansionar su poder e intervenir algo menos que otras (como la democracia, en la que no existen incentivos efectivos para que alguien se preocupe por lo que acaezca más allá de las próximas elecciones). También es cierto que, en determinadas 
circunstancias históricas, ha dado la impresión de que la marea intervencionista se había, hasta cierto punto, contenido. Pero el análisis histórico es incontrovertible: el estado no ha dejado de crecer (Hoppe, 2004). Y no ha dejado de crecer porque la mezcla del estado, como institución monopolista de la violencia, con la naturaleza humana es «explosiva». El estado impulsa y atrae como un imán de fuerza irresistible las pasiones, vicios y facetas más perversas de la naturaleza del ser humano que intenta, por un lado, evadirse de sus mandatos y, por otro, aprovecharse del poder monopolista del estado todo lo que pueda. Además, y especialmente en los entornos democráticos, el efecto combinado de la acción de los grupos privilegiados de interés, los fenómenos de miopía gubernamental y «compra de votos», el carácter megalómano de los políticos y la irresponsabilidad y ceguera de las burocracias generan un cóctel peligrosamente inestable y explosivo, continuamente zarandeado por crisis sociales, económicas y políticas que, paradójicamente, son siempre utilizadas por los políticos y «líderes» sociales para justificar ulteriores dosis de intervención que, en vez de solucionar, crean y agravan aún más los problemas.

El estado se ha convertido en el «ídolo» al que todos recurren y adoran. La estatolatría es, sin duda alguna, la más grave y peligrosa enfermedad social de nuestro tiempo. Se nos educa para creer que todos los problemas pueden y deben ser detectados a tiempo y solucionados por el estado. Nuestro destino depende del estado y los políticos que lo controlan deben garantizarnos todo lo que exija nuestro bienestar. El ser humano permanece inmaduro y se revela contra su propia naturaleza creativa (que hace ineludiblemente incierto su futuro). Exige una bola de cristal que le asegure no sólo conocer lo que va a pasar sino además que cualesquiera problemas que surjan le serán solucionados. Esta «infantilización» de las masas se fomenta de forma deliberada por los políticos y líderes sociales pues así justifican públicamente su existencia y aseguran su popularidad, situación de predominio y capacidad de control. Además una legión de intelectuales, profesores e ingenieros sociales se suman a esta arrogante borrachera del poder. 
Ni siquiera las iglesias y denominaciones religiosas más respetables han sido capaces de diagnosticar que la estatolatría es hoy en día la principal amenaza al ser humano libre, moral y responsable; que el estado es un ídolo falso de inmenso poder al que todos adoran y que no consiente que los seres humanos se liberen de su control ni tengan lealtades morales o religiosas ajenas a las que él mismo pueda dominar. Es más, ha logrado algo que a priori podría parecer imposible: distraer sinuosa y sistemáticamente a la ciudadanía de que él es el verdadero origen de los conflictos y males sociales, creando por doquier «cabezas de turco» (el «capitalismo», el ánimo de lucro, la propiedad privada) a las que culpar de los problemas y dirigir la ira popular, así como las condenas más serias y rotundas de los propios líderes morales y religiosos, casi ninguno de los cuales se ha dado cuenta del engaño ni atrevido hasta ahora a denunciar que la estatolatría es la principal amenaza en el presente siglo a la religión, a la moral y, por tanto, a la civilización humana. ${ }^{2}$

Así como la caída del Muro de Berlín en 1989 fue la mejor ilustración histórica del teorema de la imposibilidad del socialismo, el fracaso mayúsculo de los teóricos y políticos liberales a la hora de limitar el poder del estado ilustra a la perfección el teorema de la imposibilidad del estatismo y, en concreto, que el estado-liberal es en sí mismo contradictorio (por encarnar un estado-coactivo aunque sea «limitado») y teóricamente imposible

${ }^{2}$ Quizás la principal excepción más reciente esté incluida en la brillante biografía sobre Jesús de Nazaret publicada por Benedicto XVI. Que el estado y el poder político sean la encarnación institucional del Anticristo debe resultar obvio para cualquiera con mínimos conocimientos de historia que lea las consideraciones del Papa sobre la más grave tentación que puede hacernos el Maligno: «El tentador no es tan burdo como para proponernos directamente adorar al diablo. Sólo nos propone decidirnos por lo racional, preferir un mundo planificado y organizado, en el que Dios puede ocupar un lugar, pero como asunto privado, sin interferir en nuestros propósitos esenciales. Soloviev atribuye un libro al Anticristo, El camino abierto para la paz y el bienestar del mundo, que se convierte, por así decirlo, en la nueva Biblia y que tiene como contenido esencial la adoración del bienestar y la planificación racional» (Ratzinger 2007, 66-67). En el mismo sentido, pero mucho más rotundo, destaca Redford (2006), incluido en las pp. 263-324 del presente número de Procesos de Mercado. 
(pues aceptada la existencia del estado es imposible limitar el crecimiento de su poder). En suma, que el «estado de derecho» es un ideal imposible y una contradicción en los términos tan flagrante como la que supondría referirse a «la nieve caliente, a una puta virgen, a un esqueleto obeso, o a un cuadrado circular» (Jasay 1990, 35), o como en la que caen los «ingenieros sociales» y economistas neoclásicos cuando se refieren a un «mercado perfecto» o al denominado «modelo de competencia perfecta» (Huerta de Soto 2007, 347-348).

\section{VI \\ EL ANARCOCAPITALISMO COMO ÚNICO SISTEMA POSIBLE DE COOPERACIÓN SOCIAL VERDADERAMENTE COMPATIBLE CON LA NATURALEZA DEL SER HUMANO}

El estatismo es contrario a la naturaleza del ser humano pues consiste en el ejercicio sistemático y con carácter monopolista de una coacción que bloquea en todas las parcelas en donde incide (incluyendo las correspondientes a la definición del derecho y al mantenimiento del orden público) la creatividad y la coordinación empresarial que son precisamente las manifestaciones más típicas y esenciales de la naturaleza humana. Además, como ya hemos visto, el estatismo fomenta e impulsa la irresponsabilidad y corrupción moral al desviar la conducta humana hacia la utilización privilegiada de los resortes del poder político, en un entorno de ignorancia inerradicable que impide conocer qué costes genera cada acción estatal. Estos efectos del estatismo surgen siempre que exista un estado aunque se intente por todos los medios limitar su poder, objetivo éste que es imposible de lograr y que hace del liberalismo clásico una utopía científicamente irrealizable.

Es, pues, ineludible superar el «liberalismo utópico» de nuestros predecesores los liberales clásicos que, por un lado, pecaron de ingenuos al pensar que el estado podría ser limitado y, por otro, de falta de coherencia, al no asumir hasta sus últimas consecuencias las implicaciones de su propio ideario. Hoy, por tanto, 
ya bien entrado el siglo XXI, se hace prioritario asumir la superación del liberalismo clásico (utópico e ingenuo) del siglo XIX, por su nueva formulación verdaderamente científica y moderna que podemos denominar capitalismo libertario, anarquismo de propiedad privada o, simplemente, anarcocapitalismo. Y es que no tiene sentido que los liberales sigan diciendo las mismas cosas que hace ciento cincuenta años cuando en pleno siglo XXI, y a pesar de la caída del Muro de Berlín hace ya casi veinte años, los estados no han dejado de crecer y cercenar en todos los ámbitos las libertades individuales de los seres humanos.

El anarcocapitalismo es la representación más pura del orden espontáneo del mercado en el que todos los servicios, incluyendo los de definición del derecho, justicia y orden público, son proporcionados a través de un proceso exclusivamente voluntario de cooperación social que se convierte así en el objeto central de investigación de la Ciencia Económica moderna. En este sistema ninguna parcela se cierra al ímpetu de la creatividad humana y de la coordinación empresarial, potenciándose la eficiencia y la justicia en la solución de los problemas que puedan plantearse, eliminándose de raíz los conflictos, ineficiencias y desajustes que genera toda agencia monopolista de la violencia (estado) por el mero hecho de existir. Además, el sistema propuesto elimina los incentivos corruptores del ser humano que genera el estado, impulsando por contra los comportamientos humanos más morales y responsables, e impidiendo el surgimiento de ninguna agencia monopolista (estado) que legitime el uso sistemático de la violencia y la explotación por parte de unos grupos sociales (los que en cada momento mejor controlen los resortes del poder estatal) a otros (aquellos a los que no queda más remedio que obedecer).

El anarcocapitalismo es el único sistema que reconoce plenamente la libre naturaleza creativa del ser humano y su capacidad continua para asumir comportamientos pautados cada vez más morales en un entorno en el que, por definición, nadie puede arrogarse el derecho a ejercer con carácter monopolista ninguna coacción sistemática. En suma, en el anarcocapitalismo todos los proyectos empresariales pueden probarse si obtienen con carácter voluntario el apoyo suficiente, por lo que son 
múltiples las posibilidades creativas de solución que pueden idearse en un entorno dinámico y siempre cambiante de cooperación voluntaria.

La progresiva desaparición de los estados y su paulatina sustitución por un entramado dinámico de agencias privadas, por un lado patrocinadoras de diferentes sistemas jurídicos y, por otro, prestadoras de todo tipo de servicios de seguridad, prevención y defensa constituye el contenido más importante de la agenda política y científica así como el cambio social más trascendental que habrá de verificarse en el siglo XXI.

\section{VII \\ CONCLUSIÓN: IMPLICACIONES REVOLUCIONARIAS DEL NUEVO PARADIGMA}

La revolución contra el «Ancienne Règime» protagonizada en los siglos XVIII y XIX por los viejos liberales clásicos encuentra hoy su continuidad natural en la revolución anarcocapitalista del siglo XXI. Afortunadamente hemos descubierto el porqué del fracaso del liberalismo utópico y la necesidad de su superación por el liberalismo científico; y sabemos que los viejos revolucionarios erraron y pecaron de ingenuidad al perseguir un ideal imposible de alcanzar que abrió, además, las puertas a lo largo del siglo XX a las mayores tiranías estatistas que se han conocido en la historia de la humanidad.

El mensaje del anarcocapitalismo es netamente revolucionario. Revolucionario en cuanto a su objetivo: el desmantelamiento del estado y su sustitución por un proceso competitivo de mercado constituido por un entramado de agencias, asociaciones y organizaciones privadas. Revolucionario en cuanto a sus medios especialmente en los ámbitos científico, económicosocial y político.

a) Revolución científica:

Especialmente en el ámbito de la ciencia económica que se convierte en la teoría general del orden espontáneo del 
mercado extendido a todas las áreas sociales. Incorporando, además, por contraste y oposición, el análisis de los efectos de descoordinación social generados por el estatismo en cualquier parcela en que incida (incluyendo las del derecho, la justicia y el orden público). Y también el estudio de las diferentes alternativas de desmantelamiento del estado, de los procesos de transición y de las formas y efectos de la privatización integral de todos los servicios que hoy se consideran "públicos», constituyen un campo prioritario de investigación para nuestra disciplina.

b) Revolución económica y social:

No podemos siquiera intuir los inmensos logros, avances y descubrimientos humanos que podrán alcanzarse en un entorno empresarial totalmente libre del estatismo. Incluso hoy, y a pesar del continuo acoso gubernamental, ya empieza a desarrollarse en un mundo cada vez más globalizado una civilización desconocida con un grado de complejidad inabarcable e incontrolable por el poder del estatismo que alcanzará una expansión ilimitada una vez logre desembarazarse completamente del mismo. Y es que la fuerza de la creatividad de la naturaleza humana es tal que termina aflorando incluso por los resquicios más estrechos que dejan los gobiernos. Y en cuanto los seres humanos vayan adquiriendo una mayor conciencia de la naturaleza esencialmente perversa del estado que les coarta y de las inmensas posibilidades que cada día se frustran cuando éste bloquea la fuerza impulsora de su creatividad empresarial se multiplicará el clamor social en pos de la reforma, el desmantelamiento del estado y el avance hacia un futuro que nos es en gran medida desconocido pero que habrá de elevar la civilización humana a cotas que hoy ni siquiera podemos imaginar.

c) Revolución política:

Por cuanto la lucha política del día a día pasa a tener una importancia subsidiaria a lo indicado en (a) y en (b). Es cierto 
que siempre habrán de apoyarse las alternativas menos intervencionistas en clara alianza con el esfuerzo de los liberales clásicos en pos de la limitación democrática del estado. Pero el anarcocapitalista no se queda en esa labor pues sabe y debe hacer mucho más. Sabe que el objetivo final es el desmantelamiento total del estado y ello impulsa toda su imaginación y acción política en el día a día. Los avances incrementales en la buena dirección son, sin duda, bienvenidos pero sin caer jamás en un pragmatismo que traicione el objetivo último de lograr el fin del estado que, por razones pedagógicas y de influencia popular, siempre ha de perseguirse de forma sistemática y transparente ${ }^{3}$ (Huerta de Soto, 1997).

Así, por ejemplo, formarán parte de la agenda política anarcocapitalista hacer que los estados sean cada vez sean más pequeños y tengan cada vez menos poder; que a través de la descentralización autonómica y municipal a todos los niveles, el nacionalismo liberal, la reintroducción de las ciudadesminiestados, y de la secesión [Huerta de Soto (1994) (2002)] se bloquee la dictadura de las mayorías sobre las minorías y de forma creciente los seres humanos «puedan votar más con los pies que con las urnas»; que puedan, en suma, asociarse a nivel global y por encima de las fronteras para lograr los más variados fines al margen y fuera de los estados (organizaciones religiosas, clubes privados, redes de internet, etc.) (Frey, 2001).

Por otro lado, debe recordarse que las revoluciones políticas no tienen por qué ser sangrientas. Esto es especialmente cierto cuando las mismas resultan del necesario proceso de educación y maduración social, así como del clamor popular y del deseo generalizado de acabar con el engaño, la mentira y la coacción que impiden realizarse al ser humano. Así, por ejemplo, básicamente incruentas fueron la caída del Muro de Berlín y la Revolución Checa que acabó con el socialismo en el este de Europa. Y mientras se llega a este importante

${ }^{3}$ Prueba de la creciente importancia que está adquiriendo el capitalismo libertario en la actual agenda política es, por ejemplo, el artículo publicado con el título «Libertarians Rising» en la sección de Ensayos de la prestigiosa revista Time, 29 de octubre de 2007, p. 112 (Kinsley 2007). 
resultado final deben utilizarse todos los resortes pacíficos ${ }^{4}$ y legales ${ }^{5}$ que permitan los sistemas políticos actuales.

Se abre, pues, un futuro apasionante, en el que continuamente se descubrirán múltiples nuevos caminos que, en consonancia con los principios esenciales, nos permitirán avanzar en pos del ideal anarcocapitalista. Futuro que aunque hoy nos pueda parecer lejano, en cualquier momento puede ser testigo de pasos de gigante que incluso sorprendan a los más optimistas. ¿Quién fue capaz de predecir tan solo cinco años antes, que en 1989 se desmoronaría el Muro de Berlín y con él todo el comunismo del este de Europa? La historia ha entrado en un proceso acelerado de cambio que, aunque nunca se detendrá, sí que abrirá un capítulo totalmente nuevo cuando el género humano, por primera vez en la historia moderna, logre desembarazarse definitivamente del estado y reducirlo tan solo a una oscura reliquia histórica de trágica memoria.

VIII

\section{APÉNDICE GRÁFICO Y BREVE COMENTARIO SOBRE LA TRADICIÓN ANARQUISTA ESPAÑOLA}

En el Gráfico 1 se representan los diferentes sistemas políticos y la evolución natural de unos a otros clasificados en función de

\footnotetext{
${ }^{4}$ Nunca deben olvidarse las prescripciones de nuestros escolásticos del Siglo de Oro español sobre los estrictos requisitos que ha de reunir un acto de violencia para ser «justo»: $1^{\circ}$ haber agotado todas las vías y procedimientos pacíficos posibles; $2^{\circ}$ ser defensivo (frente a actos concretos de violencia) y jamás agresivo; $3^{\circ}$ proporcional en cuanto a los medios utilizados (por ejemplo, el ideal de la independencia no vale la vida o libertad de un solo ser humano); $4^{\circ}$ evitando, en todo caso, que se produzcan víctimas inocentes; $5^{\circ}$ con posibilidades de éxito (lo contrario sería un suicidio injustificable). Sabios principios a los que yo añadiría la participación y financiación exclusivamente voluntarias. Todo acto de violencia que vulnere alguno de estos principios queda automáticamente deslegitimado y se convierte en el peor enemigo del objetivo que se dice se desea alcanzar. Por último, debe traerse aquí a colación toda la teoría del tiranicidio del Padre Juan de Mariana (Mariana, 1599).

5 Como indicaba Rothbard no puede recomendarse el ir contra la «legalidad» (básicamente de mandatos administrativos) vigente pues en la inmensa mayoría de los casos no compensa en cuanto a los costes.
} 


\section{GRÁFICO 1}

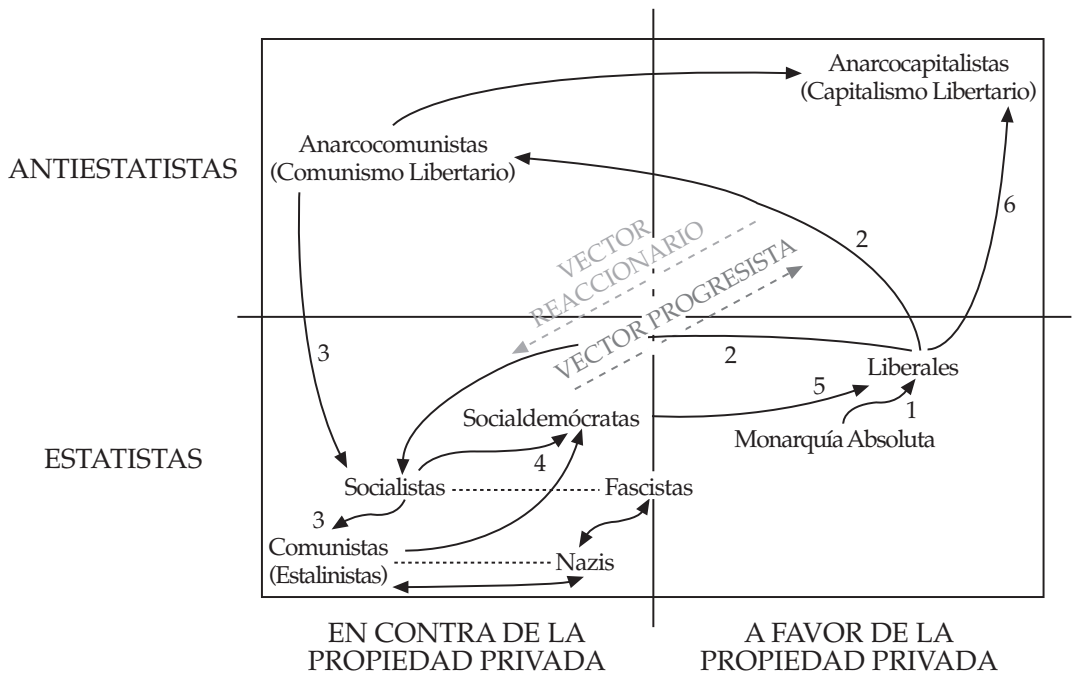

su carácter más o menos estatista y más o menos respetuoso con la propiedad privada.

Se constata cómo el inicial movimiento revolucionario (utópico y erróneo) de los liberales clásicos contra el Antiguo Régimen cae en el pragmatismo de aceptar el estado y abre las puertas a los totalitarismos socialistas (comunismo y fascismo-nazismo). La caída del socialismo real da entrada a la socialdemocracia que hoy impera por doquier (pensamiento único).

La segunda etapa, aún pendiente, de la fracasada revolución liberal (por el error e ingenuidad de los liberales clásicos) consiste precisamente en la evolución hacia el anarcocapitalismo.

Una de las consecuencias del fracaso de la revolución liberal fue la aparición del comunismo libertario, unánimemente denostado y perseguido por el resto de sistemas políticos (y en especial por los más de «izquierdas») precisamente por su carácter antiestatista. El comunismo libertario es también utópico pues al no aceptar la propiedad privada se ve abocado a utilizar la violencia sistemática (i.e., «estatal») en contra de la misma cayendo en una contradicción lógica irresoluble y bloqueando el proceso social empresarial 
que impulsa el único orden anarquista científicamente concebible: aquel constituido por el mercado libertario capitalista.

La tradición anarquista en nuestro país es de rancio abolengo. Sin olvidar sus grandes crímenes (en todo caso cuantitativa y cualitativamente inferiores a los de comunistas y socialistas) y las contradicciones en las que incurrió, constituyó, especialmente durante la España de la Guerra Civil, un experimento (abocado al fracaso) que tuvo en su momento gran respaldo social y que, al igual que sucedió con la vieja revolución liberal, tiene hoy su segunda gran oportunidad en la superación de sus errores (carácter utópico del anarquismo que niega la propiedad privada) y en la asunción del orden de mercado como única y definitiva vía hacia la supresión del estado. Si los anarquistas españoles del siglo XXI son capaces de hacer suyas estas enseñanzas de la teoría y de la historia muy probablemente España de nuevo sorprenderá al mundo (esta vez de forma general y definitiva) impulsando la vanguardia teórica y práctica de la nueva revolución anarcocapitalista.

\section{REFERENCIAS BIBLIOGRÁFICAS}

Esplugas, A. (2007). «Libertad sin estado: ¿es factible el anarcocapitalismo?», Procesos de Mercado, vol. IV, n.. 2, otoño 2007, pp. 205-253.

FreY, B. (2001). «A Utopia? Government without Territorial Monopoly», The Independent Review, vol. VI, n.. 1, verano, pp. 99-112.

HAYeK, F.A. (2006). Derecho, legislación y libertad: una nueva formulación de los principios liberales de la justicia y de la economía política, Madrid, Unión Editorial.

Hoppe, H-H (2004). Monarquía, democracia y orden natural, Madrid, Edics. Gondo.

HuerTa De SOTO, J. (1992). Socialismo, cálculo económico y función empresarial, Madrid, Unión Editorial (segunda edición de 2001, tercera edición de 2005).

- (1994). «Teoría del nacionalismo liberal», en J. Huerta de Soto, Estudios de economía política, Madrid, Unión Editorial (segunda edición de 2004). 
- (1997). «El economista liberal y la política», en Manuel Fraga: Homenaje Académico, Fundación Cánovas del Castillo, Madrid, vol. II, pp. 763-788. Reproducido en Huerta de Soto, J. (2002), Nuevos estudios de economía política, Madrid, Unión Editorial, pp. 163-192 (segunda edición de 2007).

- (1998). Dinero, crédito bancario y ciclos económicos, Madrid, Unión Editorial (segunda edición 2002, tercera edición 2006). Edición inglesa publicada con el título de Money, Bank Credit and Economic Cycles, trad. Melinda Stroup, The Ludwig von Mises Institute, Auburn, Al., USA (2006).

- (2002). «El desmantelamiento del estado y la democracia directa», capítulo 10 de Nuevos estudios de economía politica, Madrid, Unión Editorial, pp. 239-245 (Segunda edición de 2007).

- (2007). «The Essence of the Austrian School», Conferencia pronunciada en el Bundesministerium für Wissenschaft und Forchung, Viena, el 26 de marzo de 2007, publicada en Procesos de Mercado: Revista Europea de Economía Politica, vol. IV, n.o 1, primavera 2007, pp. 343-350.

JASAY, A. DE (1990). Market Socialism: A scrutiny. This Square Circle, Londres, Occasional Paper 84, Institute of Economic Affairs (IEA).

KInSLEY, M. (2007) «Libertarians Rising: The Party that reels these voters will dominate the future of American Politics», Time, 29 de octubre de 2007, p. 112.

Kirzner, I. (1985). Discovery and the Capitalist Process, Chicago y Londres, University of Chicago Press.

Mariana, Padre Juan de (1599). De rege et regis institutione, Toledo, Pedro Rodríguez.

RATZinger, J. (2007). Jesús de Nazaret, Madrid, La esfera de los libros. REDFord, J. (2006). Jesus is an Anarchist. A Free-Market, Libertarian Anarchist, That is - Otherwise what is called an Anarcho-Capitalist, http:/ / anti-state.com (1 ${ }^{\mathrm{a}}$ version Diciembre 19, 2001). Reproducido en Procesos de Mercado, vol. IV, n.․․ 2, otoño 2007, pp. 263-324

Rodríguez Braun, C. (1999). A pesar del gobierno: 100 críticas al intervencionismo con nombres y apellidos, Madrid, Unión Editorial. 